\title{
Height, weight, and body mass index of Wichí children from Formosa, Argentina
}

\author{
Marta P. Alfonso-Durruty, M.D., ${ }^{a, b}$ and Claudia R. Valeggia, M.D.
}

\begin{abstract}
This study provides the descriptive, anthropometric data of 194 children (aged 0-18 years) from a Wichí population located in the province of Formosa, Argentina. The objective of this study was to document growth and nutritional status in this indigenous people. Weight, height, and body mass index data were collected and the corresponding Z-scores were estimated using national and international reference standards. Most analyzed parameters were within the normal range. However, it is concerning that a significant percentage of children are overweight, which may indicate that this population is going through a process of westernization that promotes the consumption of high-calorie, highly-processed foods and a lower level of physical activity.
\end{abstract}

Key words: Wichi, body weight, height, body mass index.

http: / / dx.doi.org/10.5546/ aap.2018.eng.359

To cite: Alfonso-Durruty MP, Valeggia CR. Height, weight, and body mass index of Wichí children from Formosa, Argentina. Arch Argent Pediatr 2018;116(5):359-364.

Anthropology

Universidad Alberto

Hurtado, Chile.

b. Sociology,

Anthropology, and Social Work

Department, Kansas State University, United States of America.

c. Department of Anthropology, Yale University, United

States of America.

E-mail address:

Marta Alfonso-Durruty, M.D.: marta.alfonso7@ gmail.com

Funding:

National Geographic

Society, grant

no. 8395-08; L. S. B.

Leakey Foundation, unnumbered.

Conflict of interest:

None.

Received: 8-28-2017

Accepted: 3-7-2018 health, the objective of this study was to provide descriptive, anthropometric data of Wichí children from the province of Formosa, Argentina. Few studies have dealt with the biology and health of this indigenous people, and there are even fewer data available on child growth and development, ${ }^{2}$ so this study will be of great interest.

The Wichí live in the Gran Chaco region in the Northwest of Argentina (Figure 1). Originally, these semi-nomadic hunter-gatherers complemented their diet with incipient horticulture..$^{2-4}$ During the $19^{\text {th }}$ and $20^{\text {th }}$ centuries, the disruption of their lifestyle resulted in their geographic displacement and the loss of a significant number of population members. This partially explains the progressive loss of autonomy and the current situation of isolation and marginalization. ${ }^{3,4}$ The dramatic transformation of the Wichí lifestyle has been evidenced in (1) their diet, which now includes both packaged and "mountain" products, although the latter are stigmatized, and (2) the occupation of permanent settlements with limited mobility, mostly only for temporary labor migration. ${ }^{1,3}$

This study was designed as part of the Chaco Area Reproductive Ecology Program, which has worked with the Wichí and Qom peoples in the Northwest region of Argentina since 2004. The purpose of the program is to study the relationship between ecology, behavior, and biology in the indigenous and non-indigenous populations of the Gran Chaco area. The results described here correspond to one of the main objectives of the program: to provide data on child growth and development in different ecologies and socio-cultural settings. 


\section{MATERIAL AND METHODS}

\section{Design and population}

This was a cross-sectional, quantitative study, and the data presented here were collected between July 2008 and June 2009. All families were invited to participate; male and female children aged 0-18 years were recruited and, at the time of study initiation, a population census was conducted to estimate the representativeness of the participants in relation to the total population.

\section{Description of the study setting and procedures}

The study population lived in the community of Pozo de Maza, located $50 \mathrm{~km}$ north of Ingeniero Juárez (Figure 1), where the Wichí people had a central community (1300 individuals) and four small communities (50-120 individuals). Their mixed diet was made up of purchased foods and mountain items they hunted, fished, and gathered., ${ }^{1,2}$ Families lived mainly on stateprovided social benefits and goods provided by political groups. In Pozo de Maza there was a province-run health care center with a primary care physician, a pediatrician who worked intermittently, and indigenous health workers.

Children who had one or more of the following were excluded from the study: (1) Down syndrome, (2) a twin also participating in the study, (3) pregnancy, (4) unknown date of birth. All participants were categorized by age and sex. Age was estimated based on the date of birth as reported by parents, which was corroborated with the child's national identity document or other official record (medical record or birth certificate).

Children aged 0.0-0.99 years were divided into three age categories $(0.0,0.25$, and 0.75 years), according to the recommendations for Z-score estimations using the Argentine reference ${ }^{5}$ (see below). Data were collected at the house of participants under parental supervision. Height and weight were measured using a portable stadiometer (SECA 213 ${ }^{\circledR}$ ) and an electronic scale (Tanita $\mathrm{TBF}^{\odot}$ ), respectively. The scale was calibrated at the health care center using a counterweight scale at study initiation. Weight and height data were used to estimate the body mass index (BMI, $\mathrm{kg} / \mathrm{m}^{2}$ ). At study initiation (July 2008), reliability controls were carried out with the main investigator $(\mathrm{CV})$ and field assistants to check the anthropometric measures mentioned above. Training was completed once a $95 \%$ agreement was reached. Height measurements in children younger than 7 years were not considered reliable enough; therefore, height data are presented for boys 7-14 years old and girls 7-18 years old. The cultural idiosyncrasy and characteristics typical of adolescence prevented us from including boys older than 14 years in the study. Children's assent and parents' informed consent were obtained before data collection.

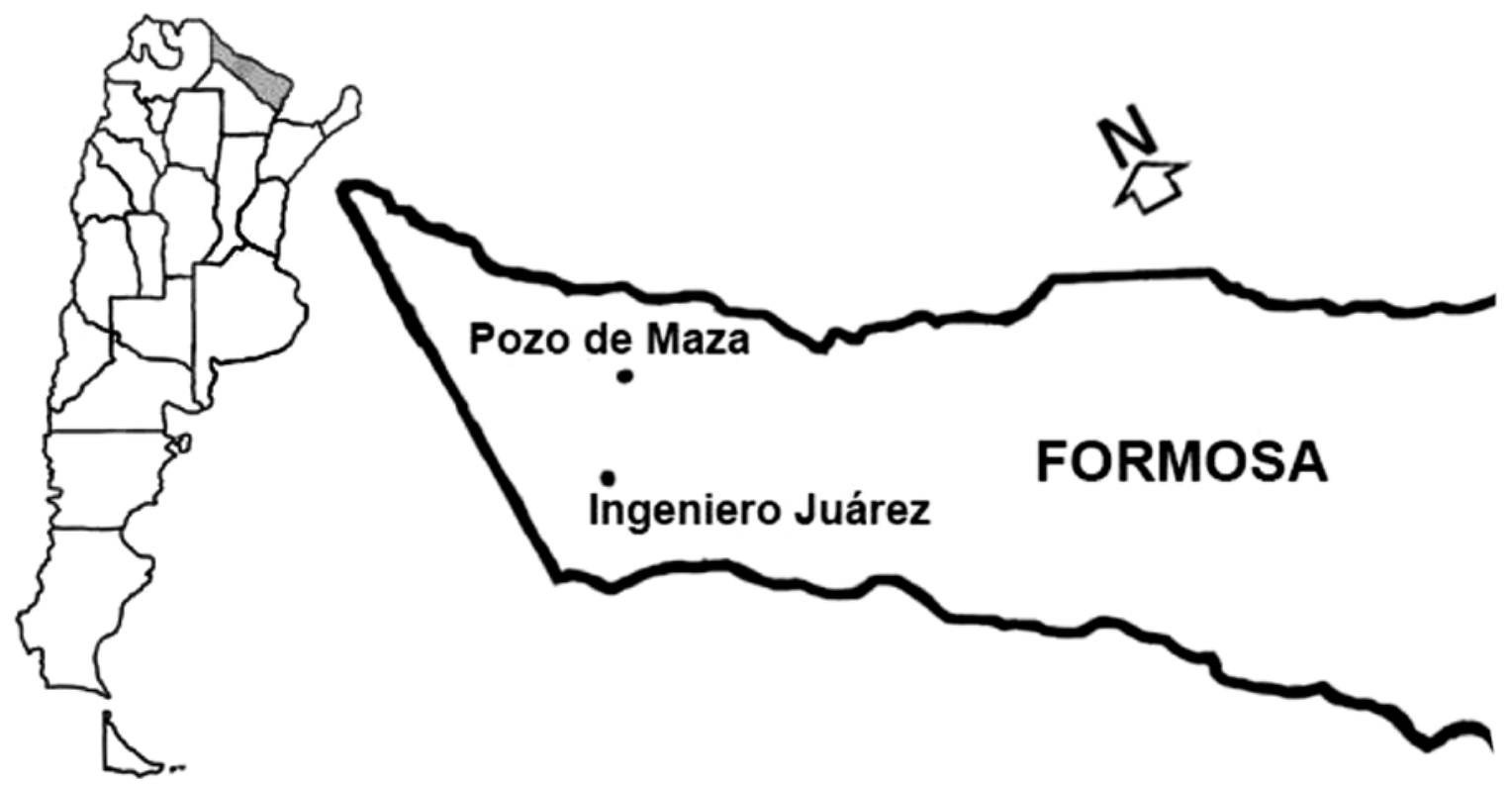


The study protocol was approved by the Ethics Committee of the University of Pennsylvania, United States of America (USA). The information regarding participants with overweight/obesity, malnutrition and/or delayed growth was shared with the local health care center.

The height-for-age Z-score (HAZ), weight-forage Z-score (WAZ), and body-mass-index-Z-score (BMIZ) were estimated with the lambda-musigma (LMS) method, ${ }^{6}$ using international (int.).,8 and Argentine (nat.) ${ }^{5}$ reference values. The international reference was used to estimate the HAZint score, the WAZint score (only up to 10 years old due to its limitations), and the BMIZint score. The national reference was used to estimate the HAZnat and WAZnat scores. Individual Z-scores for height and BMI were interpreted according to the World Health Organization's guidelines (HAZ $<-2=$ delayed growth, $<-3=$ severe delay, BMIZ $>+3=$ obese, $>+2=$ overweight, $>1=$ risk for overweight, $<-2=$ underweight, $<-3=$ severely underweight). ${ }^{9}$ The statistical analyses were done using the SPSS 21.0 software. ${ }^{10}$

\section{RESULTS}

One hundred and ninety-seven $(\mathrm{n}=197)$ children were originally selected for participation, but three $(n=3)$ girls were excluded from the study because they were pregnant. Therefore, one hundred and ninety-four $(\mathrm{n}=194)$ participants were included in this study. The number of male $(n=95)$ and female $(n=99)$ children was similar and, according to the population census conducted at the time of study initiation, they accounted for $96 \%$ (99 out of $\mathrm{n}=103$ ) and $89 \%$ (95 out of $\mathrm{n}=110$ ) of girls and boys aged $0-18$ years, respectively (see Tables 1 and 2). Table 1 shows the weight, height, and BMI of Wichí girls. Girls' height (HAZint and HAZnat) is normal at all ages, but values are mostly below the mean (Table 1). This trend deepens in girls aged 1418 years, whose HAZint and HAZnat scores are lower. Individual HAZint and HAZnat scores are normal in $96.5 \%(n=55)$ of girls. However, two $(n=2,3.5 \%)$ girls showed delayed growth.

Among the girls, the WAZint and WAZnat scores are mostly normal; they group around the mean and are consistently above it over the first

TABLE 1. Height $(\mathrm{cm})$, weight $(\mathrm{kg})$, body mass index $\left(\mathrm{kg} / \mathrm{m}^{2}\right)$, and Z-scores of Wichi girls $(\mathrm{N}=99)$

\begin{tabular}{|c|c|c|c|c|c|c|c|c|c|c|c|c|c|c|c|c|c|}
\hline \multirow[b]{3}{*}{ Age (years) } & \multirow[b]{3}{*}{$\mathbf{n}$} & \multicolumn{6}{|c|}{ ANTHROPOMETRIC DATA } & \multicolumn{6}{|c|}{$\begin{array}{l}\text { INTERNATIONAL } \\
\text { REFERENCE }\end{array}$} & \multicolumn{4}{|c|}{$\begin{array}{l}\text { NATIONAL } \\
\text { REFERENCE }\end{array}$} \\
\hline & & \multicolumn{2}{|c|}{ HA } & \multicolumn{2}{|c|}{ WA } & \multicolumn{2}{|c|}{ BMI } & \multicolumn{2}{|c|}{ HAZint } & \multicolumn{2}{|c|}{ WAZint } & \multicolumn{2}{|c|}{ BMIZint } & \multicolumn{2}{|c|}{ HAZnat } & \multicolumn{2}{|c|}{ WAZnat } \\
\hline & & Mean & SD & Mean & SD & Mean & SD & Mean & SD & Mean & SD & Mean & SD & Mean & SD & Mean & SD \\
\hline 0.00 & 0 & & & & & & & & & & & & & & & & \\
\hline 0.25 & 3 & & & 6.3 & 0.8 & & & & & 0.6 & 1.1 & & & & & 0.6 & 1.0 \\
\hline 0.5 & 1 & & & 8.7 & & & & & & 1.4 & & & & & & 1.4 & \\
\hline 0.75 & 6 & & & 9.0 & 1.0 & & & & & 0.7 & 0.9 & & & & & 0.7 & 0.9 \\
\hline 1 & 3 & & & 10.2 & 1.4 & & & & & 1.0 & 1.0 & & & & & 1.0 & 1.0 \\
\hline 2 & 3 & & & 12.0 & 1.2 & & & & & 0.3 & 0.8 & & & & & 0.3 & 0.8 \\
\hline 3 & 5 & & & 14.4 & 2.4 & & & & & 0.2 & 1.3 & & & & & 0.00 & 1.4 \\
\hline 4 & 7 & & & 14.4 & 2.3 & & & & & -0.9 & 1.2 & & & & & -1.2 & 1.4 \\
\hline 5 & 9 & & & 17.9 & 1.8 & & & & & -0.2 & 0.6 & & & & & -0.1 & 0.8 \\
\hline 6 & 6 & 112.0 & & 19.4 & 1.1 & 15.9 & & -0.6 & & -0.3 & 0.4 & 0.4 & & -0.2 & & -0.3 & 0.4 \\
\hline 7 & 10 & 120.8 & 5.1 & 23.1 & 2.7 & 15.8 & 1.1 & 0.0 & 0.9 & 0.1 & 0.7 & 0.2 & 0.6 & 0.4 & 0.94 & 0.1 & 0.8 \\
\hline 8 & 3 & 126.3 & 9.5 & 29.3 & 9.3 & 18.0 & 3.1 & -0.04 & 1.6 & 0.7 & 1.6 & 0.9 & 1.2 & 0.4 & 1.6 & 0.6 & 1.6 \\
\hline 9 & 10 & 131.0 & 4.8 & 27.1 & 4.2 & 15.7 & 1.6 & -0.2 & 0.8 & -0.3 & 0.9 & -0.3 & 0.8 & 0.3 & 0.8 & -0.3 & 0.9 \\
\hline 10 & 9 & 136.9 & 5.3 & 32.1 & 3.6 & 17.1 & 1.6 & -0.3 & 0.8 & 0.0 & 0.7 & 0.2 & 0.8 & 0.3 & 0.8 & 0.1 & 0.6 \\
\hline 11 & 1 & 144.0 & & 39.8 & & 19.2 & & -0.1 & & & & 0.8 & & 0.4 & & 0.6 & \\
\hline 12 & 8 & 148.1 & 7.9 & 44.9 & 8.2 & 20.5 & 3.3 & -0.5 & 1.2 & & & 0.7 & 1.1 & 0.12 & 1.0 & 0.5 & 1.0 \\
\hline 13 & 3 & 152.7 & 3.1 & 46.4 & 2.6 & 19.9 & 1.0 & -0.5 & 0.4 & & & 0.4 & 0.3 & -0.03 & 0.4 & 0.1 & 0.3 \\
\hline 14 & 5 & 151.6 & 4.5 & 52.9 & 4.5 & 22.9 & 1.1 & -1.2 & 0.6 & & & 1.0 & 0.3 & -0.8 & 0.6 & 0.5 & 0.5 \\
\hline 15 & 1 & 143.0 & & 47.8 & & 23.4 & & -2.7 & & & & 0.9 & & -2.6 & & -0.5 & \\
\hline 16 & 3 & 153.0 & 3.0 & 50.1 & 6.4 & 21.4 & 2.8 & -1.4 & 0.4 & & & 0.1 & 0.98 & -1.2 & 0.5 & -0.4 & 1.1 \\
\hline 17 & 1 & 155.0 & & 51.9 & & 21.6 & & -1.2 & & & & 0.2 & & -0.9 & & -0.2 & \\
\hline 18 & 2 & 151.0 & 9.9 & 56.5 & 13.9 & 24.5 & 2.9 & -1.8 & 1.5 & & & 0.9 & 0.7 & -1.6 & 1. & 0.2 & 1.8 \\
\hline
\end{tabular}

WA: weight-for-age; HA: height-for-age; BMI: body mass index; SD: standard deviation; HAZint: international height-for-age Z-score; WAZint: international weight-for-age Z-score; BMIZint: international body mass index Z-score; HAZnat: national height-for-age Z-score; WAZnat: national weight-for-age Z-score. 
three years of life (0-3 years; Table 1). Between 4 and up to 7 years old, the WAZint and WAZnat scores are mostly below the mean (Table 1), but they reverse to positive values as of 7-8 years old, with some exceptions (Table 1). Girls' BMIZint scores are grouped around the international mean value; they are mostly in the range of normal and predominately positive (Table 1 ). The analysis of individual results shows that $78.9 \%(n=45)$ of girls have a normal BMIZint score, whereas $17.5 \%$ are at risk of overweight $(n=10)$. The two remaining girls $(n=2,3.5 \%)$ were overweight.

The weight, height, and BMI of boys are shown in Table 2. The HAZint and HAZnat scores indicate that boys' height is mostly below the mean, even though it groups around it (Table 2). The analysis of individual HAZint and HAZnat scores shows that most children have a normal height (HAZint $=95.6 \%$, HAZnat $=97.8 \%$ ). The remaining boys showed delayed growth $(\mathrm{n}=2$, HAZint $=4.3 \% ; \mathrm{n}=1$, HAZnat $=2.2 \%$ ).

Boys' WAZint and WAZnat scores are mainly negative, but they tend to fall within the normal range (Table 2). However, high, positive values are observed in the first year of life (Table 2). BMIZ scores group around the international average (Table 2). The analysis of individual BMIZint scores indicates that $84.8 \%$ of boys $(n=39)$ have a normal BMI, $13.0 \%$ are at risk for overweight $(n=6)$, and one $(n=1,2.2 \%)$ is underweight.

\section{DISCUSSION}

The analysis of anthropometric data shows that, in this Wichí population, most children are within the range of normality according to the international and national growth reference standards. However, although the HAZint and HAZnat scores were normal, they indicate that Wichí boys' and girls' height was mostly below the mean of the reference standard. Moreover, although it was infrequent, girls showed delayed growth. These results suggest that the growth conditions of Wichí children need to be improved.

In both boys and girls, the WAZ scores are predominately positive during the first year of life, which may be explained by the extended breastfeeding practiced by this group of people. At later ages, WAZ scores tend to turn negative, although, in general, they are within the normal range.

TABLE 2. Height ( $\mathrm{cm})$, weight $(\mathrm{kg})$, body mass index $(\mathrm{kg} / \mathrm{m} 2)$, and Z-scores of Wichí boys $(\mathrm{N}=95)$

\begin{tabular}{|c|c|c|c|c|c|c|c|c|c|c|c|c|c|c|c|c|c|}
\hline \multirow[b]{3}{*}{ Age (years) } & \multirow[b]{3}{*}{$\mathbf{n}$} & \multicolumn{6}{|c|}{ ANTHROPOMETRIC DATA } & \multicolumn{6}{|c|}{$\begin{array}{l}\text { INTERNATIONAL } \\
\text { REFERENCE }\end{array}$} & \multicolumn{4}{|c|}{$\begin{array}{l}\text { NATIONAL } \\
\text { REFERENCE }\end{array}$} \\
\hline & & \multicolumn{2}{|c|}{ HA } & \multicolumn{2}{|c|}{ WA } & \multicolumn{2}{|c|}{ BMI } & \multicolumn{2}{|c|}{ HAZint } & \multicolumn{2}{|c|}{ WAZint } & \multicolumn{2}{|c|}{ BMIZint } & \multicolumn{2}{|c|}{ HAZnat } & \multicolumn{2}{|c|}{ WAZnat } \\
\hline & & Mean & SD & Mean & SD & Mean & SD & Mean & SD & Mean & SD & Mean & SD & Mean & SD & Mean & SD \\
\hline 0.00 & 1 & & & 3.9 & & & & & & 1.1 & & & & & & 1.2 & \\
\hline 0.25 & 0 & & & & & & & & & & & & & & & & \\
\hline 0.5 & 1 & & & 9.8 & & & & & & 2.0 & & & & & & 1.9 & \\
\hline 0.75 & 3 & & & 9.2 & 1.4 & & & & & 0.2 & 1.4 & & & & & 0.2 & 1.4 \\
\hline 1 & 8 & & & 9.3 & 1.4 & & & & & -0.4 & 1.3 & & & & & -0.4 & 1.4 \\
\hline 2 & 4 & & & 12.2 & 0.1 & & & & & 0.1 & 0.1 & & & & & 0.0 & 0.1 \\
\hline 3 & 7 & & & 14.3 & 0.6 & & & & & -0.0 & 0.4 & & & & & -0.2 & 0.4 \\
\hline 4 & 9 & & & 15.3 & 3.5 & & & & & -0.8 & 2.4 & & & & & -1.0 & 2.5 \\
\hline 5 & 9 & & & 16.4 & 4.1 & & & & & -1.2 & 2.3 & & & & & -1.4 & 2.5 \\
\hline 6 & 7 & & & 19.5 & 2.7 & & & & & -0.5 & 1.1 & & & & & -0.5 & 1.1 \\
\hline 7 & 4 & 117.7 & 2.0 & 22.8 & 0.6 & 16.5 & 0.5 & -0.8 & 0.4 & -0.0 & 0.2 & 0.7 & 0.3 & -0.5 & 0.4 & -0.1 & 0.2 \\
\hline 8 & 7 & 123.1 & 4.8 & 24.5 & 1.9 & 16.2 & 1.3 & -0.7 & 0.9 & -0.3 & 0.6 & 0.2 & 0.8 & -0.5 & 0.9 & -0.4 & 0.5 \\
\hline 9 & 8 & 130.0 & 6.0 & 26.6 & 3.2 & 15.7 & 1.6 & -0.4 & 1.0 & -0.4 & 0.8 & -0.3 & 1.1 & -0.2 & 1.0 & -0.5 & 0.8 \\
\hline 10 & 11 & 134.5 & 5.7 & 30.1 & 4.4 & 16.6 & 1.4 & -0.5 & 0.9 & -0.3 & 1.0 & -0.0 & 0.8 & -0.2 & 0.9 & -0.4 & 0.9 \\
\hline 11 & 5 & 139.0 & 6.9 & 34.4 & 4.3 & 17.8 & 2.3 & -0.6 & 1.0 & & & 0.3 & 1.1 & -0.2 & 1.0 & -0.2 & 0.8 \\
\hline 12 & 4 & 142.7 & 10.8 & 34.5 & 5.6 & 16.8 & 0.3 & -0.9 & 1.5 & & & -0.4 & 0.2 & -0.4 & 1.4 & -0.8 & 1.0 \\
\hline 13 & 2 & 161.5 & 0.7 & 53.1 & 4.4 & 20.4 & 1.5 & 0.7 & 0.1 & & & 0.8 & 0.5 & 1.2 & 0.1 & 0.9 & 0.4 \\
\hline 14 & 4 & 159.2 & 3.6 & 46.9 & 5.7 & 18.4 & 1.8 & -0.5 & 0.5 & & & -0.3 & 0.8 & 0.1 & 0.4 & -0.4 & 0.7 \\
\hline 15 & 0 & & & & & & & & & & & & & & & & \\
\hline 16 & 0 & & & & & & & & & & & & & & & & \\
\hline 17 & 0 & & & & & & & & & & & & & & & & \\
\hline 18 & 1 & 169.0 & & 71.6 & & 25.1 & & -1.0 & & & & 1.0 & & -0.5 & & 0.7 & \\
\hline
\end{tabular}

WA: weight-for-age; HA: height-for-age; BMI: body mass index; SD: standard deviation; HAZint: international height-for-age Z-score; WAZint: international weight-for-age Z-score; BMIZint: international body mass index Z-score; HAZnat: national height-for-age Z-score; WAZnat: national weight-for-age Z-score. 
The reduction in height is more marked than that in weight (compared to reference values), because, although the BMIZint scores are mostly normal, $21 \%$ of girls and $13 \%$ of boys are at risk for or are overweight. This is particularly relevant because more than one third of the adult Wichí population is overweight. ${ }^{1}$ This pattern is common among South American indigenous peoples who are going through a nutritional transition, including neighboring indigenous communities. ${ }^{11,12}$ Overweight values observed in this study are similar to those seen in Qom children living in rural communities in the Northwest of Argentina. ${ }^{13}$

This indicates that rural Wichí children are part of the westernization process, characterized by the introduction of a market economy, an increased consumption of processed foods, reduced physical activity, and, in the case of Wichí groups, the cultural detraction of traditional food sources. ${ }^{1,2,14,15}$

The social causes of overweight among Wichí children require further studies that would consider the effects of external factors, such as political and religious programs in the area, which have cut down the access to mountain products, and the detraction of the traditional lifestyle. Childhood overweight and obesity are worldwide health problems that especially affect indigenous peoples, and their health consequences are far-reaching. ${ }^{16-18}$

In the particular case of the Wichí people, adult overweight and obesity are associated with a high socio-economic status, which is the result of the considerable social communication with non-indigenous political groups, ${ }^{1}$ which reinforces the idea that diet modifications are caused by an acculturation process.

This study provides exclusive data in relation to the Wichí people in the Northwest region of Argentina. However, the number of participants is limited, although it accounts for a high percentage of the Wichí people from Pozo de Maza. Future studies should include larger samples and consider the development of longitudinal studies that document changes in these anthropometric indicators over the growth and development period of these children.

Our experience of more than 20 years working in the province of Formosa suggests that it is necessary to have a health policy that includes the traditional knowledge of indigenous peoples and a holistic approach to their social and cultural situation that would allow to reach these individuals, many times discriminated or directly forgotten, in a more effective manner. This is no easy challenge given the structural and ideological barriers that usually affect these populations. However, we trust that gaining more knowledge about this reality -leaving biased political interests aside- and making bigger efforts to include the indigenous peoples in the conversation will make it possible to design better strategies and act accordingly.

\section{CONCLUSION}

The weight and height of Wichí children are mostly within the range of normality established by national and international parameters. However, whereas national and international HAZ scores are mostly below the mean, the assessment of the BMIZ score shows that $13 \%$ of Wichí boys and $21 \%$ of Wichí girls are at risk for or are overweight. These results indicate that the Wichí peoples are going through a process of westernization that favors a change in their diet and lifestyle that leaves them overweight and obese.

\section{REFERENCES}

1. Valeggia CR, Burke KM, Fernandez-Duque E. Nutritional status and socioeconomic change among Toba and Wichí populations of the Argentinean Chaco. Econ Hum Biol 2010; 8(1):100-10.

2. Lanza NA, Valeggia CR. Sobrepeso y obesidad en una población WichídelOeste Formoseño: prevalencia y efectos bioculturales. Rev Argent Antropol Biol 2005; 7(1):155.

3. Parolín ML, Carnese FR. HLA-DRB1 alleles in four Amerindian populations from Argentina and Paraguay. Genet Mol Biol 2009; 32(2):212-9.

4. Alvarsson, J-A. The Mataco of the Gran Chaco: an ethnographic account of change and continuity in Mataco socio-economic organization. Uppsala: Academiae Upsaliensis; 1988.

5. Lejarraga $\mathrm{H}$, del Pino M, Fano V, et al. Referencias de peso y estatura desde el nacimiento hasta la madurez para niñas y niños argentinos. Incorporación de datos de la OMS de 0 a 2 años, recálculo de percentilos para la obtención de valores LMS. Arch Argent Pediatr 2009; 107(2):126-33.

6. Cole TJ. The LMS method for constructing normalized growth standards. Eur J Clin Nutr 1990; 44(1):45-60.

7. WHO Multicentre Growth Reference Study Group. WHO Child Growth Standards based on length/height, weight and age. Acta Paediatr Suppl 2006; 450:76-85.

8. World Health Organization. Child Growth Standards: Methods and Development: Head Circumference-for-Age, Arm Circumference-for-Age, Triceps Skinfold-for-Age and Subscapular Skinfold-for-Age. Geneva: WHO; 2007.

9. World Health Organization. Training Course on Child Growth Assessment. WHO Child Growth Standards. Genova: WHO; 2008.

10. IBM Corp. IBM SPSS Statistics for Windows, Version 21.0. Armon, NY: IBM Corp.; 2012.

11. Tanner S, Leonard WR, Reyes-García V, et al. The consequences of linear growth stunting: influence on body composition among youth in the Bolivian Amazon. Am J Phys Anthropol 2014; 153(1):92-102. 
12. Urlacher SS, Blackwell AD, Liebert MA, et al. Physical growth of the shuar: Height, Weight, and BMI references for an indigenous amazonian population. Am J Hum Biol 2016; 28(1):16-30.

13. Alfonso-Durruty MP, Valeggia CR. Growth patterns among indigenous Qom children of the Argentine Gran Chaco. Am J Hum Biol 2016; 28(6):895-904.

14. Valeggia C, Lanza NA, Córdoba L. Fuentes de variación en la alimentación actual de los Toba-Pilagá del oeste formoseño. Actas del Quinto Congreso de Americanistas, Sociedad Argentina de Americanistas. Buenos Aires; 2005. Pages.123-42.

15. Gordillo G. Locations of Hegemony: The Making of Places in the Toba's Struggle for La Comuna, 1989-99. Am Anthropol 2002; 104(1):262-77.
16. NCD Risk Factor Collaboration (NCD-RisC). Worldwide trends in body-mass index, underweight, overweight, and obesity from 1975 to 2016: a pooled analysis of 2416 population-based measurement studies in 128.9 million children, adolescents, and adults. Lancet 2017; 390(10113):2627-42.

17. Ernst MA, Gerver WJ, Simons MY, et al. Obesity in childhood: a secular trend or an epidemic disease? J Child Health Care 2013; 17(1):30-40.

18. ThearleMS, VotrubaSB, Piaggi P, et al. The effect of differing patterns of childhood body mass index gain on adult physiology in American Indians. Obesity (Silver Spring) 2015; 23(9):1872-80. 